\title{
O rio Paraguai no megaleque do Nabileque, sudoeste do Pantanal Mato-Grossense, MS
}

\author{
Sidney Kuerten ${ }^{1,2}$ \& Mario Luis Assine ${ }^{2}$
}

\begin{abstract}
Resumo O megaleque fluvial do Nabileque é um sistema deposicional que vem sendo construído pelo rio Paraguai na borda sudoeste do Pantanal Mato-Grossense desde tempos pleistocênicos. É um sistema aluvial peculiar, pois não está associado a rios oriundos de relevos altos situados nos planaltos adjacentes à planície. Trata-se de um megaleque fluvial construído pelo rio Paraguai, rio-tronco coletor das águas de todo sistema hidrográfico do Pantanal, na saída do rio para a planície do Chaco, onde coalesce com o megaleque do Pilcomayo. Fazendo uso de dados de sensores remotos, com verificação de campo, foi possível compartimentar e caracterizar geomorfologicamente o megaleque, que ocupa área aproximada de $9.100 \mathrm{~km}^{2}$. A maior parte da área é uma vasta planície aluvial desenvolvida sobre depósitos pleistocênicos, marcada pela presença de intrincada rede de paleocanais distributários e de tributários a eles superimpostos. Feições erosivas evidenciam que as áreas de ocorrência dos depósitos pleistocênicos se encontram em degradação, mas sujeitas a frequentes inundações responsáveis pela existência de delgadas e irregulares coberturas de sedimentos recentes. Um aspecto notável de sua geomorfologia é a existência de dois cinturões de meandros, um ativo e outro abandonado. O vale corta o megaleque longitudinalmente, ajustado a padrões de fratura NE do lineamento Transbrasiliano, com deflexão para SSE ao se encontrar com o rio Negro (Bolívia), com o qual compõe a drenagem periférica do leque. O rio Nabileque corre num vale inciso de direção norte-sul e empresta seu nome ao megaleque e à região (Pantanal do Nabileque). Processos de avulsão fluvial e de captura são aventados e discutidos para explicar a notável mudança de curso do rio Paraguai e a configuração do rio Nabileque como um rio subajustado. O rio Nabileque é um rio com dimensões muito inferiores às paleogeoformas encontradas na sua planície, o que permite ser reconhecido como um rio subajustado.
\end{abstract}

Palavras-chave: Pantanal, rio Paraguai, megaleque fluvial, vale inciso, rio subajustado.

\begin{abstract}
The Paraguay River on the Nabileque fluvial megafan, southwest of the Pantanal wetland, Brazil. The Nabileque fluvial fan is a Quaternary depositional system located along the southwestern border of the Pantanal, covering an area of approximately $9,100 \mathrm{~km}^{2}$. It is a peculiar alluvial system because it is not associated with inflow from adjacent plateaus. The Nabileque megafan is formed by the Paraguay River at the exit of the Pantanal wetland, coalescing with the Pilcomayo megafan of the Chaco basin. A geomorphological zonation analysis was performed making use of remote sensing data with field verification. Most of the area is a vast alluvial plain made of Pleistocene deposits, whose surface is marked by the presence of an intricate network of distributary paleochannels. Areas blanketed by Pleistocene deposits are dissected by erosional streams and subject to frequent flooding events. The Paraguay River flows in a meander belt constrained by NE fractures associated with the Transbrasiliano Lineament, but deflects towards the SSE after the Negro River confluence composing the system's peripheral drainage. An abandoned meander belt is preserved within a remarkable N-S incised-valley that is interpreted as the ancient Paraguay River course. Processes of avulsion and river capture are suggested to explain the observed changes of the river course. The Nabileque River is an underfit stream within the incised-valley, cutting paleomeanders and point bars of the previous Paraguay River course.
\end{abstract}

Keywords: Pantanal wetland, Paraguay River, fluvial megafan, incised-valley, underfit stream.

INTRODUÇÃO O Pantanal Mato-Grossense ocupa área de aproximadamente 138 mil km² na Região Centro-Oeste do Brasil, estendendo-se também por territórios da Bolívia e do Paraguai. É uma extensa planície aluvial alojada na Depressão do Alto Paraguai, com altitudes inferiores a $200 \mathrm{~m}$ em relação ao nível do mar (Fig. 1). Sua superfície é marcada pela presença de amplo trato deposicional formado por megaleques fluviais, sendo o do Taquari, com cerca de $50.000 \mathrm{~km}^{2}$, o maior deles
(Assine 2005, Zani et al. 2009). Muitas das feições morfológicas existentes no Pantanal são reliquiares, testemunhando complexa evolução paleogeográfica que vem ocorrendo desde o Pleistoceno (Tricart 1982, Ab'Saber 1988, Soares et al. 2003, Assine \& Soares 2004).

Fluindo de norte para sul, o rio Paraguai coleta as águas de todos os rios que drenam os planaltos circunvizinhos e chegam à planície do Pantanal. Após a antiga confluência do rio Taquari, à jusante da localidade

1 - Universidade Estadual de Mato Grosso do Sul, Jardim (MS), Brasil. E-mail: sidneykuerten@yahoo.com.br

2 - Departamento de Geologia Aplicada, Instituto de Geociências e Ciências Exatas/IGCE - Programa de Pós-graduação em Geociências e Meio Ambiente, Universidade Estadual Paulista, Rio Claro (SP), Brasil. E-mail: assine@rc.unesp.br 


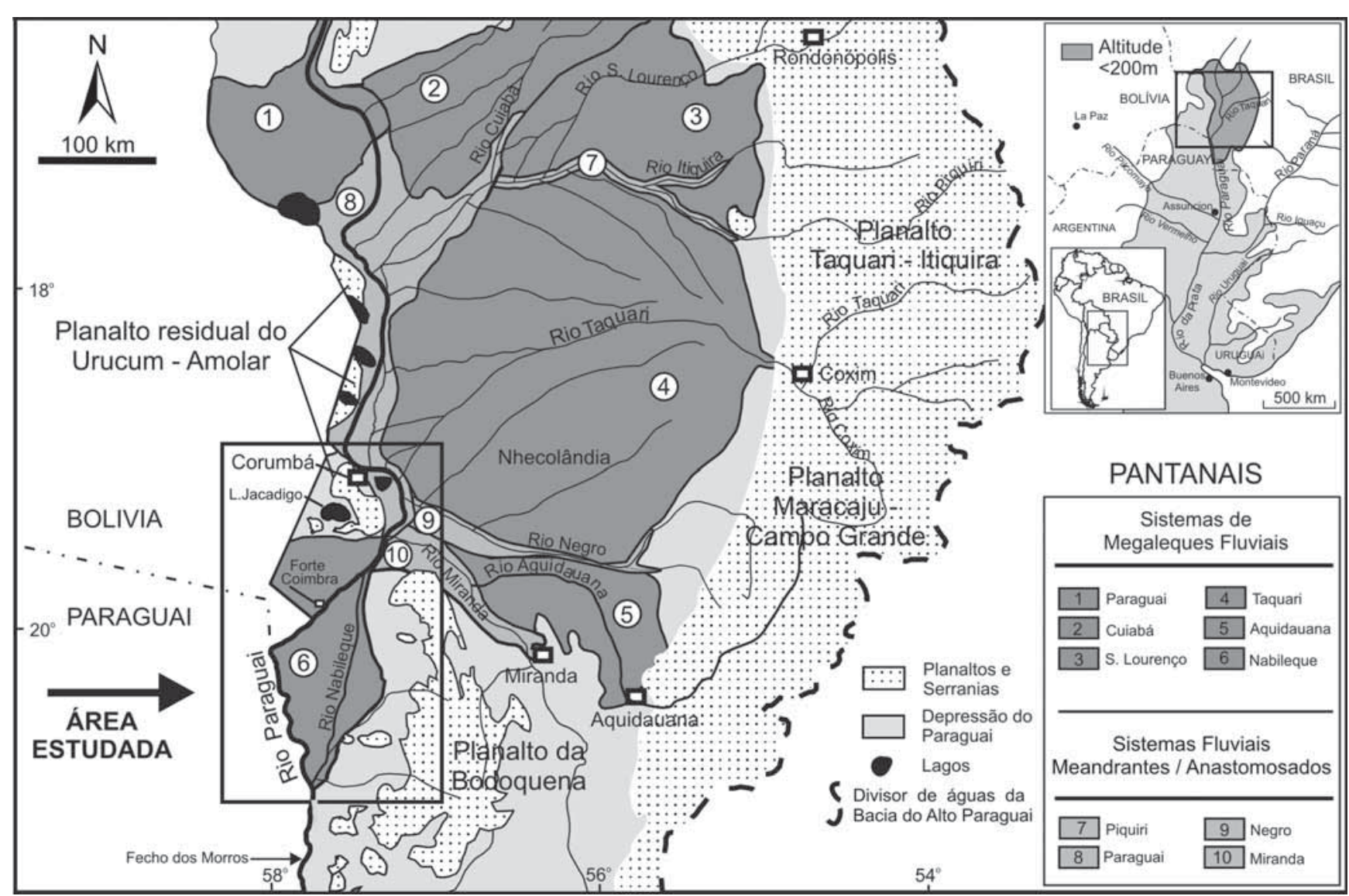

Figura 1 - Sistemas deposicionais do Pantanal com localização da área estudada (modificado de Assine \& Silva 2009).

de Porto da Manga (Assine et al. 2005), a planície fluvial do rio Paraguai estreita-se ao passar por entre os planaltos da Bodoquena e do Urucum, para novamente se abrir no extremo sudoeste do Pantanal, numa área conhecida como Pantanal do Nabileque. Esta área, localizada entre as bacias sedimentares do Pantanal e do Chaco, apresenta espessuras sedimentares menores que $100 \mathrm{~m}$ (Assine 2004).

O Pantanal do Nabileque também é caracterizado pela presença de um megaleque fluvial, mas que apresenta muitas características morfológicas e hidrológicas que o distinguem do restante do Pantanal, a começar pelo fato de que por ele passa toda a água drenada na bacia hidrográfica do Alto Paraguai. Além disso, a área experimenta inundação tardia em relação às outras áreas do Pantanal, com defasagem de até quatro meses quando comparada com o período de cheia do rio Paraguai no norte da bacia (Sippel et al. 1995).

As geoformas fluviais existentes na paisagem do megaleque do Nabileque são registros inequívocos de importantes mudanças paleogeográficas e paleo-hidrológicas ocorridas na área desde o final do Pleistoceno. Destaca-se a existência de um cinturão de meandros abandonado, que, de acordo com Ab'Saber (1988) é o mais notável exemplo de paleocanal de todo o Pantanal.

Considerando que a caracterização física é muito importante para o planejamento do uso e ocupação territorial da área, bem como para esforços de preservação e conservação, e que a reconstituição das mudanças ambientais tem papel fundamental para o entendimento da evolução quaternária do Pantanal, este trabalho tem por objetivos o compartimento geomorfológico do megaleque, a caracterização dos estilos fluviais do rio Paraguai, o reconhecimento de mudanças paleogeográficas e paleo-hidrológicas, a interpretação de processos de sedimentação e erosão, e a formulação de modelo evolutivo para explicar a sucessão de eventos que originaram a atual paisagem.

MÉTODOS E MEIOS A análise foi realizada com base na interpretação de imagens de satélite Landsat (NASA 2000, GeoCover S21/15 e S21/20). Para a compartimentação geomorfológica foram também interpretados dados de outros sensores remotos, tais como imagens do satélite ASTER (VNIR e SWIR) e dados altimétricos georreferenciados da missão SRTM. O arcabouço geológico foi baseado nas cartas geológicas do Brasil ao Milionésimo (folhas SE21 Corumbá e SF21 Campo Grande).

Um banco de dados conforme padrão proposto por Zeiler (1999), com uma interface de manipulação de informações geográficas (Litton 1987), foi construído para a análise dos dados disponíveis. O procedimento inicial consistiu no tratamento de imagens orbitais e na construção de modelos digitais de elevação (MDEs) com dados SRTM. As imagens GeoCover receberam 
tratamento de contraste para realçar elementos geomorfológicos. O MDE da área estudada foi gerado a partir da redução dos intervalos das classes altimétricas com a edição da paleta de cores para ressaltar a geomorfologia. Os ajustes de redução dos intervalos altimétricos aplicados ao MDE resultaram num ganho qualitativo da imagem, com aumento da representatividade, permitindo a diferenciação de feições geomorfológicas de baixa amplitude topográfica (Fig. 2).

Três campanhas de campo, realizadas de 2006 a 2008 nos períodos de seca (outubro/novembro), forneceram importantes dados para a validação das interpretações feitas com dados de sensores remotos, permitindo caracterização mais detalhada e amostragem das diferentes unidades.

O trabalho consistiu na delimitação da área do Pantanal do Nabileque e de seus compartimentos com relação a unidades do seu entorno, buscando-se verificar a presença de feições geomorfológicas deposicionais (canais ativos, paleocanais, barras em pontal, lagos em meandros abandonados, terraços marginais, planícies etc.) e degradacionais (vales encaixados e terraços). Atenção especial foi dada à identificação de paleocanais e planícies fluviais, pois suas formas testemunham mudanças hidrológicas e ambientais ocorridas na área estudada.

RESULTADOS O megaleque do Nabileque possui formato alongado, com ápice a nordeste, situado nas proximidades da confluência do rio Miranda (Fig. 3). Limita-se a norte com o Planalto residual do Urucum, a leste/sudeste com a planície do rio Miranda e com o planalto da Bodoquena, e a oeste/sudoeste com as franjas dos megaleques coalescentes do rio Tucavaca (Bolívia) e do rio Pilcomayo (Paraguai) (Fig. 4). Possui maior extensão, de aproximadamente $170 \mathrm{~km}$, na direção NS, cobrindo área de cerca de $9.100 \mathrm{~km}^{2}$.
Com exceção de poucos morros isolados residuais, a topografia da região é muito plana com altitudes que variam de $90 \mathrm{~m}$ na porção proximal a $70 \mathrm{~m}$ na sua porção distal situada na extremidade sul. Os MDEs revelaram nitidamente a geometria do megaleque, bem como dos sistemas aluviais adjacentes na Bolívia e no Paraguai, além da existência de pequenos leques aluviais provenientes das encostas do Planalto da Bodoquena. Vale destacar que as feições fortemente orientadas de direção N60E e N60W, que cruzam o centro da imagem da figura 4, não têm significado geomorfológico, constituindo artefatos devido a erros da Banda $\mathrm{C}$ da missão SRTM (e.g., Bhang et al. 2007).

Três unidades geomorfológicas distintas foram reconhecidas na planície do megaleque (Fig. 5): a) planície aluvial distributária degradada; b) cinturão de meandros abandonado; e c) cinturão de meandros atual.

Planície aluvial distributária degradada A planície aluvial degradada ocupa a maior parte do megaleque, possui baixo gradiente topográfico e é suavemente inclinada para SW. Sua superfície é marcada por uma intrincada trama de paleocanais distributários de sinuosidade variável e com sentido de fluxo para o quadrante SW.

Além de paleocanais distributários de baixa sinuosidade, com evidências de pontos de rompimento de diques marginais, há também na planície geoformas deposicionais que testemunham épocas em que a planície foi dominada pela presença de rios meandrantes, especialmente conspícuos na margem direita do vale do Nabileque (Fig. 6).

A paleodrenagem está sendo obliterada devido à implantação de canais mais jovens, de natureza erosiva e/ou agradacional, chamados de corixos e vazantes (denominação local), que compõe uma rede tributária de natureza intermitente (Fig. 6). Os principais rios desta
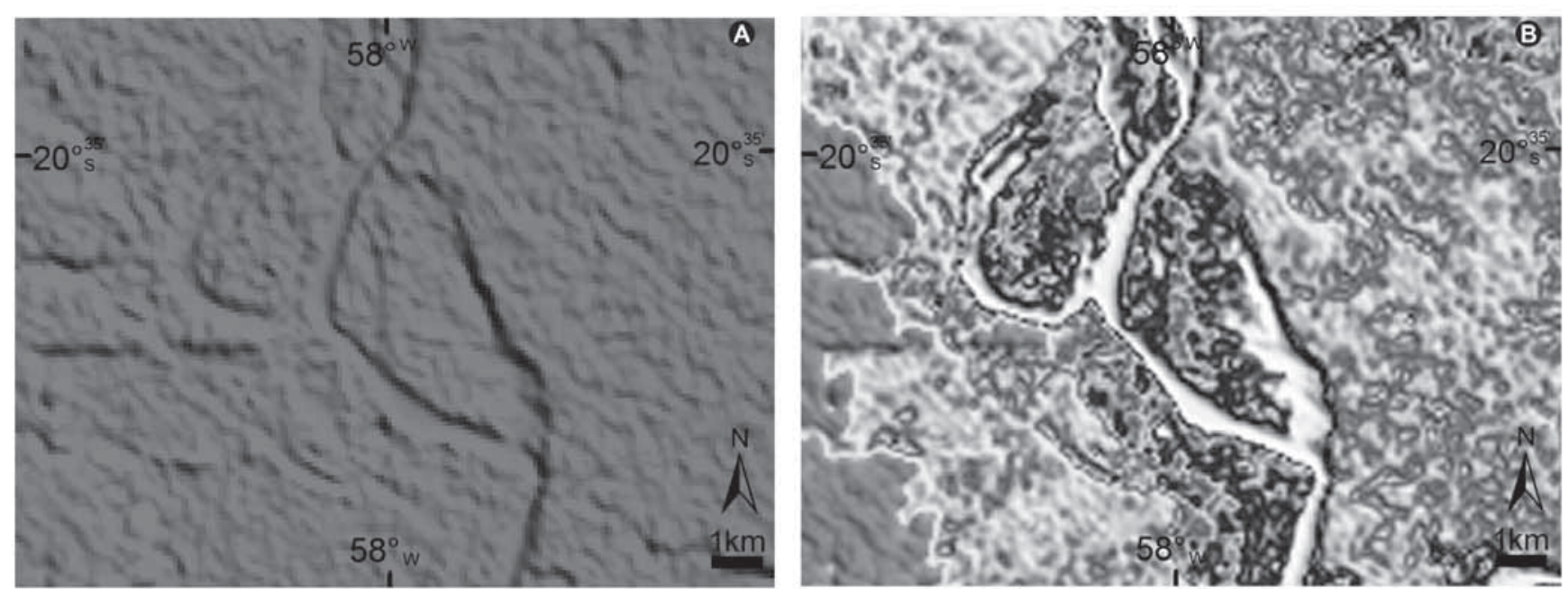

Figura 2 - Comparação de modelos digitais de elevação (MDE's) da planicie do rio Paraguai, gerados a partir de dados SRTM: A) MDE SRTM sem ajustes; B) MDE SRTM com ajuste nos intervalos de classe mostra significativo ganho de qualidade, permitindo caracterizar com mais precisão feições geomorfológicas em área com pequenas diferenças altimétricas. 


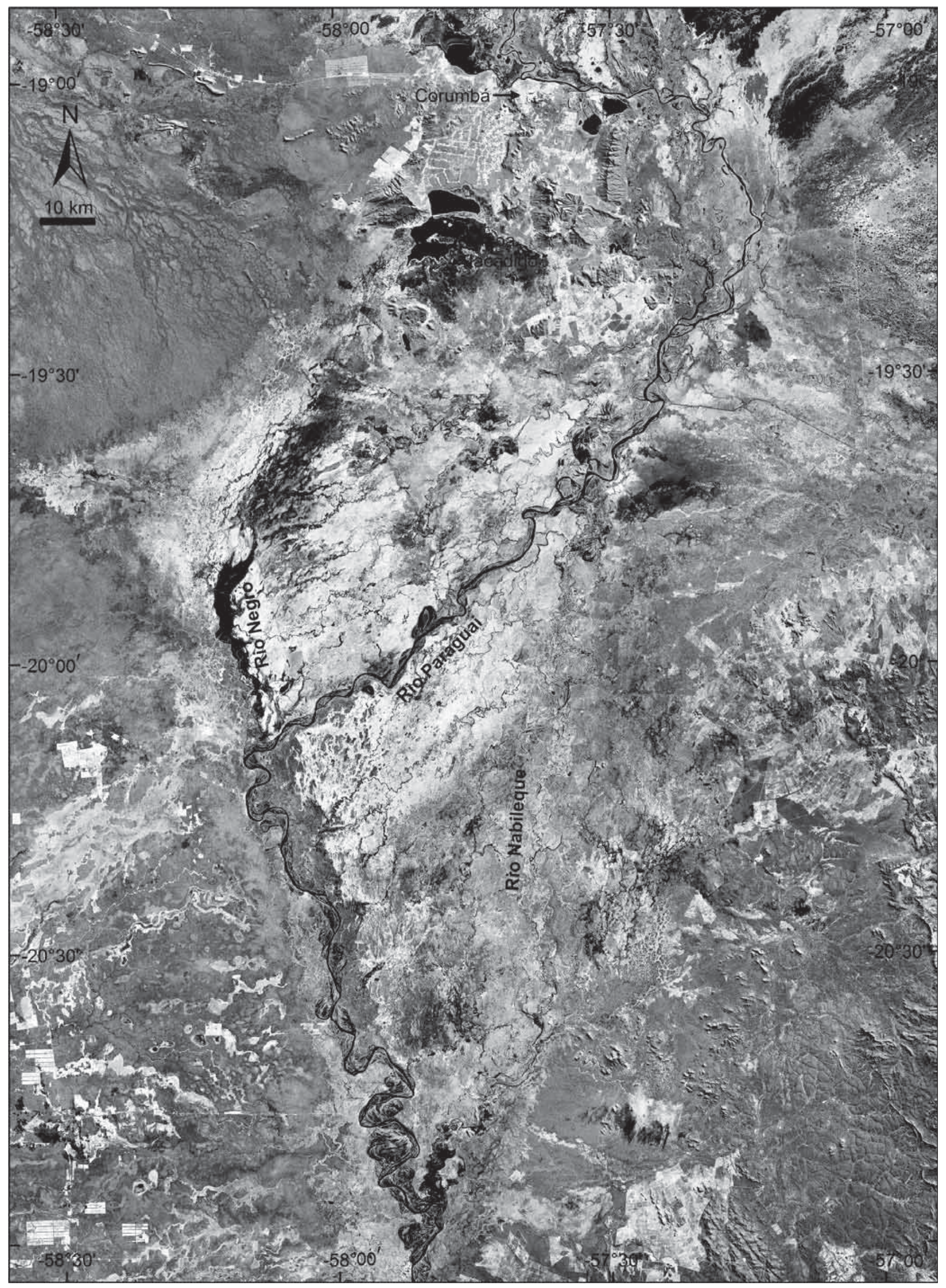

Figura 3 - Pantanal do Nabileque em imagem de satélite (mosaico Geocover Circas - 7R4G2B de 06/2001). 


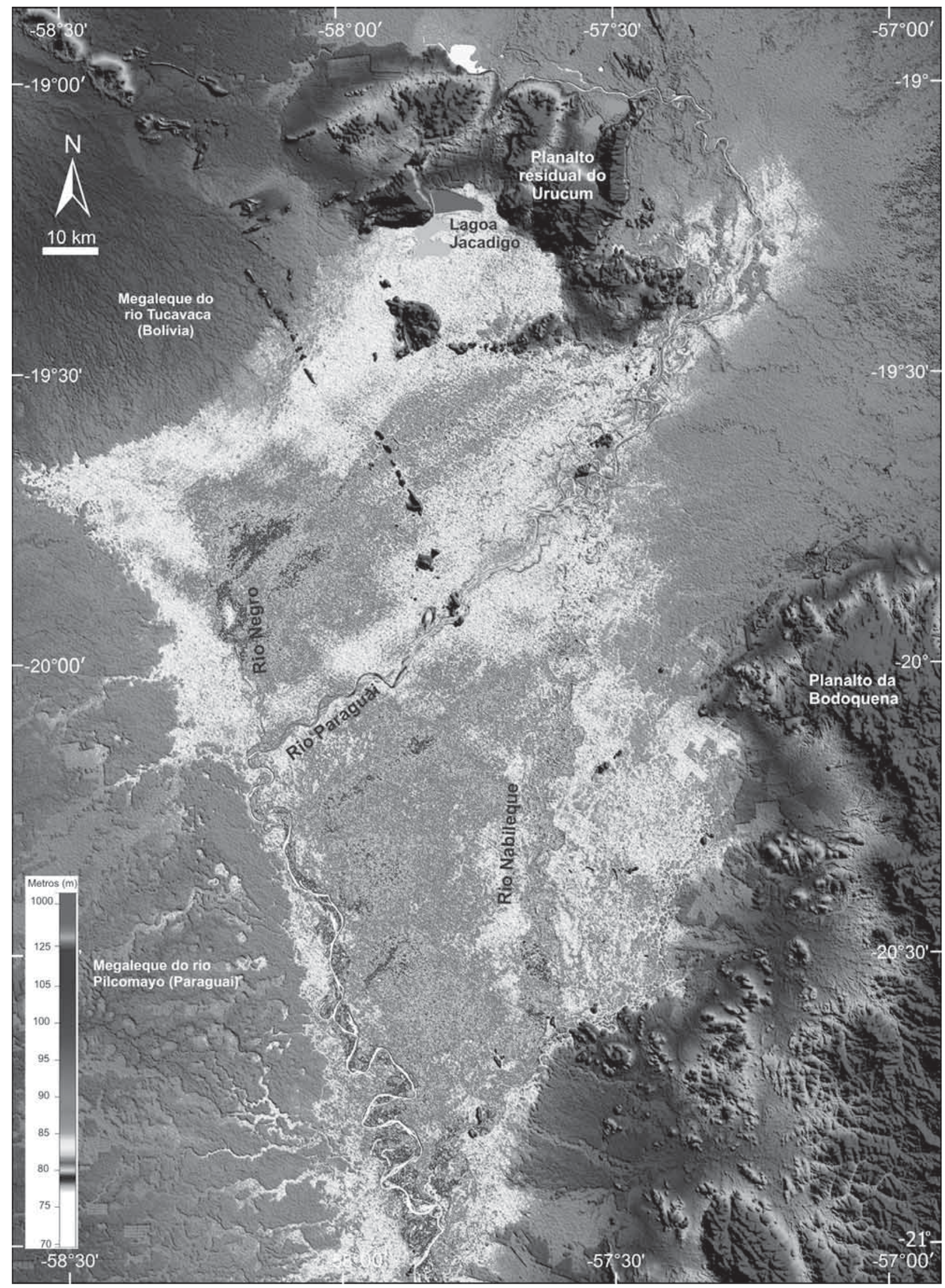

Figura 4 - MDE da área estudada. A superficie do Pantanal do Nabileque está representada em tons claros entre as cotas de 70 e $85 \mathrm{~m}$. Relevos adjacentes contrastam com a área estudada por possuir amplitude altimétrica muito maior. As feições fortemente orientadas de direção N60E e N60W são artefatos decorrentes de erros da Banda C da missão SRTM. 


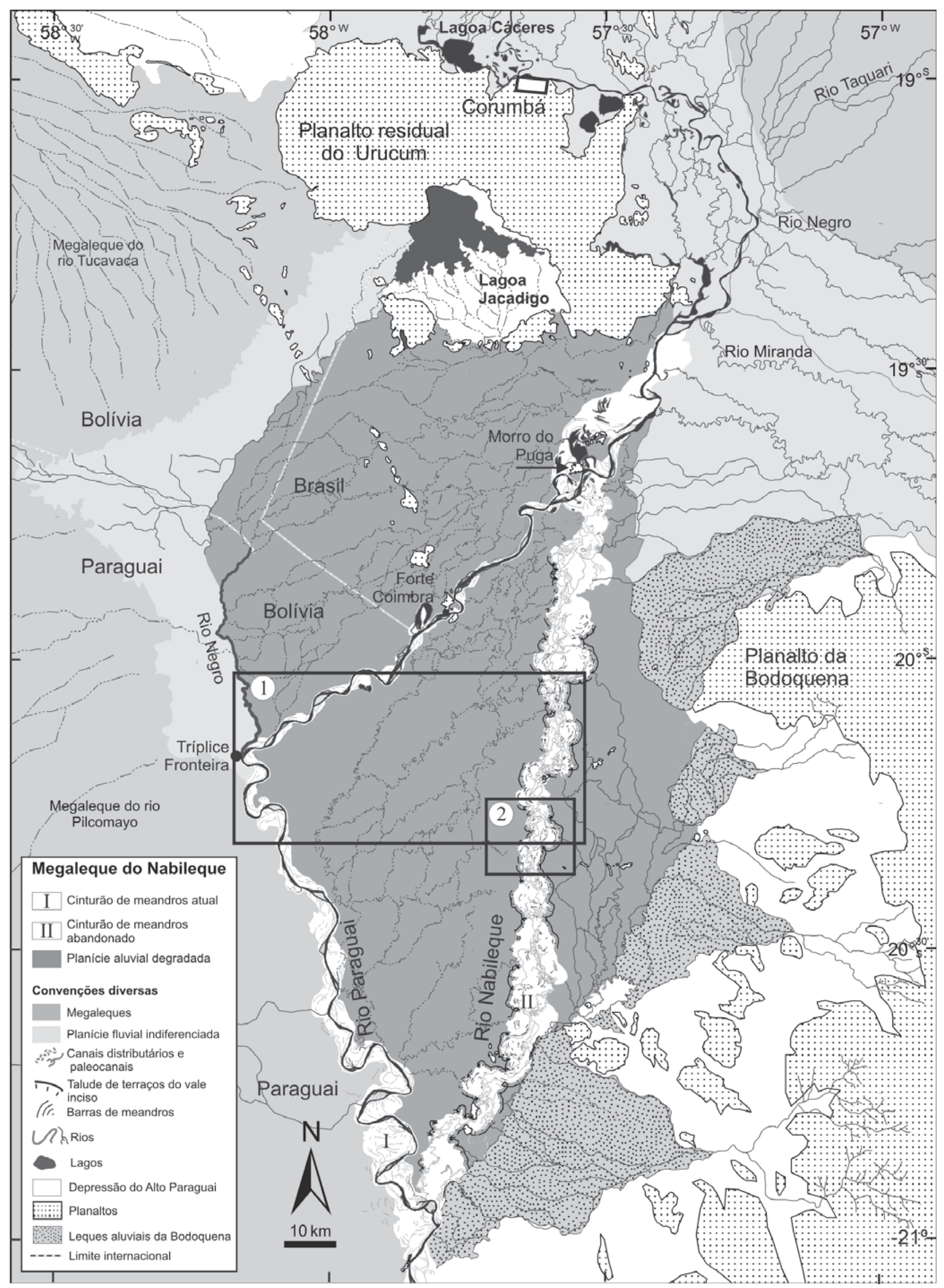

Figura 5 - Mapa geomorfológico do Pantanal do Nabileque (1 = localização da figura 6; 2 = localização da figura 7). 
rede de drenagem tributária superimposta têm largura média inferior a $100 \mathrm{~m}$ e sinuosidade variável (índice de até 1,95), podendo apresentar meandros irregulares e barras em pontal. Durante os períodos úmidos estes canais são reativados e passam a drenar as águas para áreas mais baixas, situadas na franja do leque, onde são coletadas pelos rios Negro e Paraguai, que funcionam como drenagem periférica do leque.

$\mathrm{Na}$ borda noroeste do megaleque existe um extenso e pouco profundo corpo de água intermitente, formado numa área topograficamente mais baixa, entre relevos residuais do Maciço de Urucum (Fig 4). Denominada lagoa Jacadigo, esta área recebe fluxo aluvial vindo do conjunto de morrarias circunvizinhas, águas das cheias do rio Paraguai e de canais efêmeros dos megaleques adjacentes (Nabileque e Tucavaca). As águas da lagoa são drenadas pelo rio Negro, que compõe a drenagem periférica do leque e é afluente da margem direita do rio Paraguai.

Cinturão de meandros abandonado A planície aluvial degradada é cortada por um notável paleovale inciso, de direção norte-sul, no qual se encontra alojado um cinturão de meandros abandonado (Fig. 5). O vale inciso possui largura média de $5,2 \mathrm{~km}$ e é limitado por terraços descontínuos com sutil desnível topográfico, normalmente inferior a $2 \mathrm{~m}$ (Fig. 7A).

$\mathrm{O}$ cinturão de meandros exibe complexa e intrincada rede de paleocanais, com grande quantidade de espiras de meandro (scroll bars), de elevado grau de curvatura e variadas dimensões. Formas meandrantes semelhantes encontradas fora do paleovale, em nível topográfico superior, constituem geoformas fluviais mais antigas pertencentes à planície aluvial degradada (Fig. 7B).

$\mathrm{O}$ rio Nabileque nasce dentro do vale inciso, nas proximidades da margem direita do rio Paraguai, percorrendo cerca de $150 \mathrm{~km}$ dentro do cinturão de meandros abandonado, que funciona como sua planície de inundação (Fig. 3). O rio possui regime hidrológico perene, sendo também alimentado pelas águas que extravasam do rio Paraguai durante suas cheias, e por águas provenientes de leste, dos contrafortes do Planalto da Bodoquena.

Em seu curso para sul, até sua foz no rio Paraguai, o rio Nabileque corta ou se ajusta a feições relictas do cinturão de meandros abandonado, sendo frequente a ocorrência de bifurcações e confluências de seus canais, contornando ilhas vegetadas ou antigas barras estabilizadas, o que permite classificar seu padrão fluvial como anastomosado. Os canais exibem formas e dimensões muito inferiores às dos paleocanais e barras em pontal que compõem o cinturão de meandros abandonado. $\mathrm{O}$ canal tem largura média de $60 \mathrm{~m}$, podendo atingir $400 \mathrm{~m}$ em alguns pontos. $\mathrm{O}$ traçado de alguns dos canais é difícil de ser delineado em imagens de satélite porque suas águas ficam cobertos por macrófitas, ou porque suas margens ficam submersas durante as inundações, ou ainda porque secam durante períodos de estiagem.
Durante período de grandes cheias, todo o cinturão de meandros fica inundado, e as águas de inundação extravasam os limites ocidentais do vale inciso, através de canais que cortam a superfície aluvial degradada e que conduzem as águas para a franja do leque e, finalmente, para a planície atual do rio Paraguai (Fig. 3).

Cinturão de meandros atual $\mathrm{O}$ cinturão de meandros atual, por onde flui o rio Paraguai, apresenta dois setores com distintas características. O primeiro setor tem início no ápice do megaleque e se estende por cerca de $90 \mathrm{~km}$ até a foz do rio Negro, na tríplice fronteira entre Brasil, Bolívia e Paraguai (Fig. 5). O rio Paraguai possui canal orientado na direção SW, possui largura média de $390 \mathrm{~m}$, apresenta baixa sinuosidade (índice de 1,2$)$ e o cinturão de meandros é estreito, com largura média de $1,7 \mathrm{~km}$. O rio é predominantemente erosivo, ora retrabalhando barras de meandros existentes no cinturão, ora entalhando lateralmente terraços de depósitos aluviais mais antigos. Destaque para o fato de que, do ápice do leque até a foz do rio Negro, as altitudes decrescem das margens do canal para as planícies adjacentes, de forma que o cinturão de meandros está implantado em área topograficamente mais alta que o restante do megaleque (Fig. 4).

$\mathrm{O}$ rio muda bruscamente seu curso para SE a jusante da foz do rio Negro e permanece neste rumo por cerca de $160 \mathrm{~km}$ até a foz do rio Nabileque. De montante para jusante, há incremento na sinuosidade do canal e na largura da planície. No cinturão de meandros, barras em pontal de maior sinuosidade são truncadas por barras mais jovens formadas pela migração lateral do canal atual. Neste segundo setor, o rio Paraguai define o limite entre os megaleques coalescentes do Nabileque (Brasil) e do Pilcomayo (Paraguai), constituindo drenagem periférica que coleta as águas de ambos os sistemas.

DISCUSSÃO DOS RESULTADOS A idade dos depósitos antigos do megaleque do Nabileque é considerada pleistocênica por correlação com depósitos similares do megaleque do Taquari (Assine 2003, Assine \& Soares 2004). A superfície de tais depósitos é marcada pela presença de paleocanais distributários e de paleocanais meandrantes (Figs. 3 e 6).

Um aspecto marcante na geomorfologia do megaleque é a existência de um cinturão de meandros de direção norte-sul, semelhante ao atual, mas abandonado. Neste cinturão corre o rio Nabileque, um rio de canal estreito em relação à largura dos paleocanais existentes na planície onde corre (Fig. 7), o que o caracteriza como um rio subajustado (underfit stream). O tamanho dos meandros abandonados e das barras em pontal é compatível com as dimensões do atual rio Paraguai, de forma que é consistente a interpretação de que este cinturão de meandros abandonado não foi formado pelo atual rio Nabileque, mas sim pelo rio Paraguai antes de sua mudança para seu atual curso. Desta forma, mais do que um notável exemplo de paleocanal (Ab'Saber 1988), o cinturão de meandros é um 


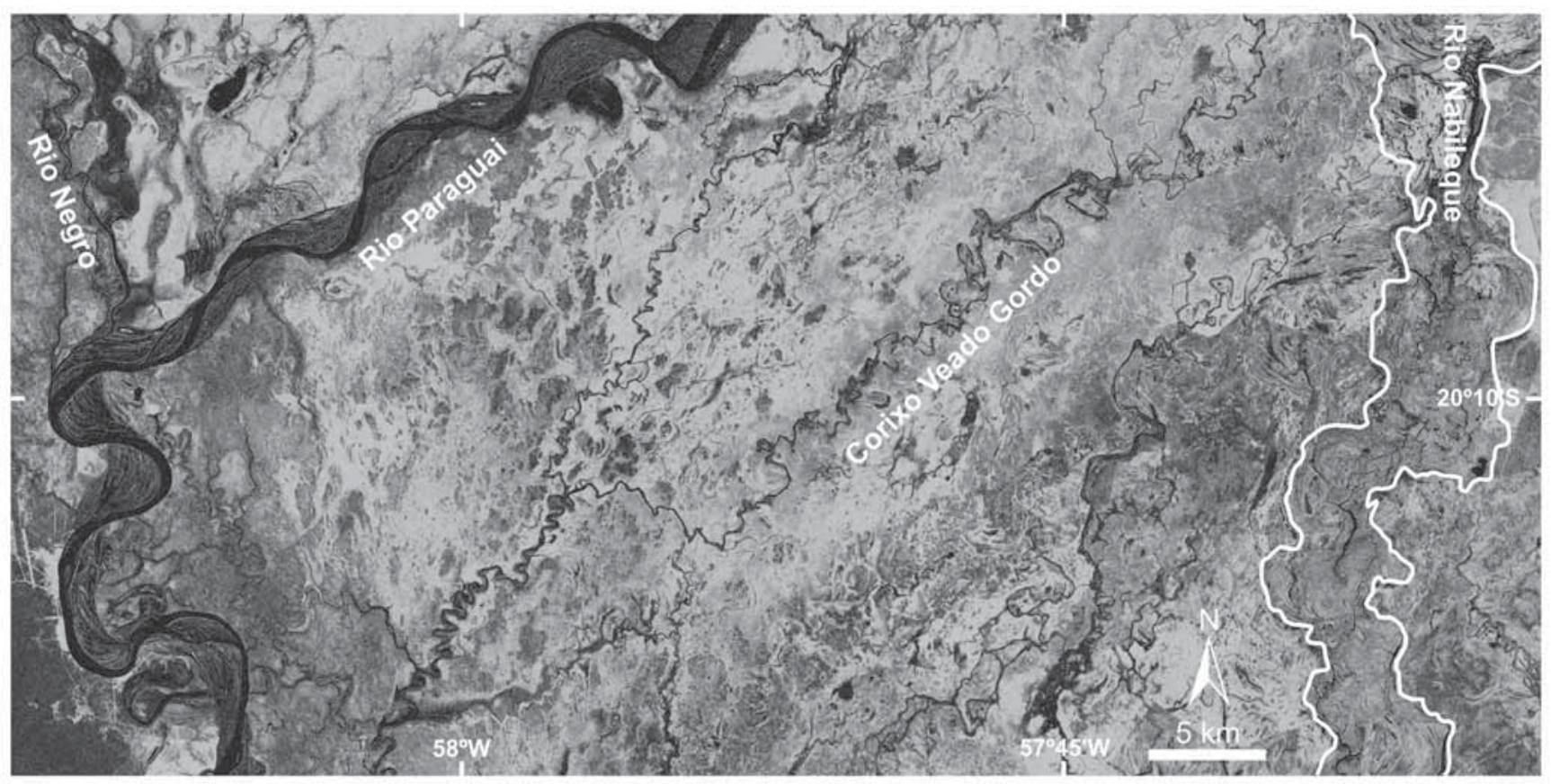

Figura 6 - Canais tributários superimpostos na planície aluvial em degradação, da qual o Corixo Veado Gordo é um exemplo. Na imagem também pode ser observado o cinturão de meandros atual (esquerda) e cinturão de meandros abandonado (direita) (imagem Geocover Circas 2000 - banda 7, 06/2001).

impressionante exemplo de um cinturão de meandros abandonado, que agradou um paleovale inciso em depósitos aluviais antigos.

Embora o rio Paraguai corra confinado num vale estreito e a maior parte da área do megaleque seja representada por depósitos aluviais antigos, cuja superfície esteja degradada, em maior ou menor grau, pela superimposição de drenagem tributária (Fig. 6), o sistema como um todo é afetado no período das cheias, quando ocorre transbordamento dos canais e fluxos em lençol inundam quase toda a área, erodindo, retrabalhando e redepositando sedimentos, o que contribui para mascarar muitos dos paleocanais. As inundações ocorrem principalmente nas porções norte e oeste, topograficamente mais baixas, e no paleocinturão de meandros onde flui o rio Nabileque (Fig. 8). Durante as inundações, os paleocanais do sistema distributário do megaleque do Nabileque são reativados e drenam as águas
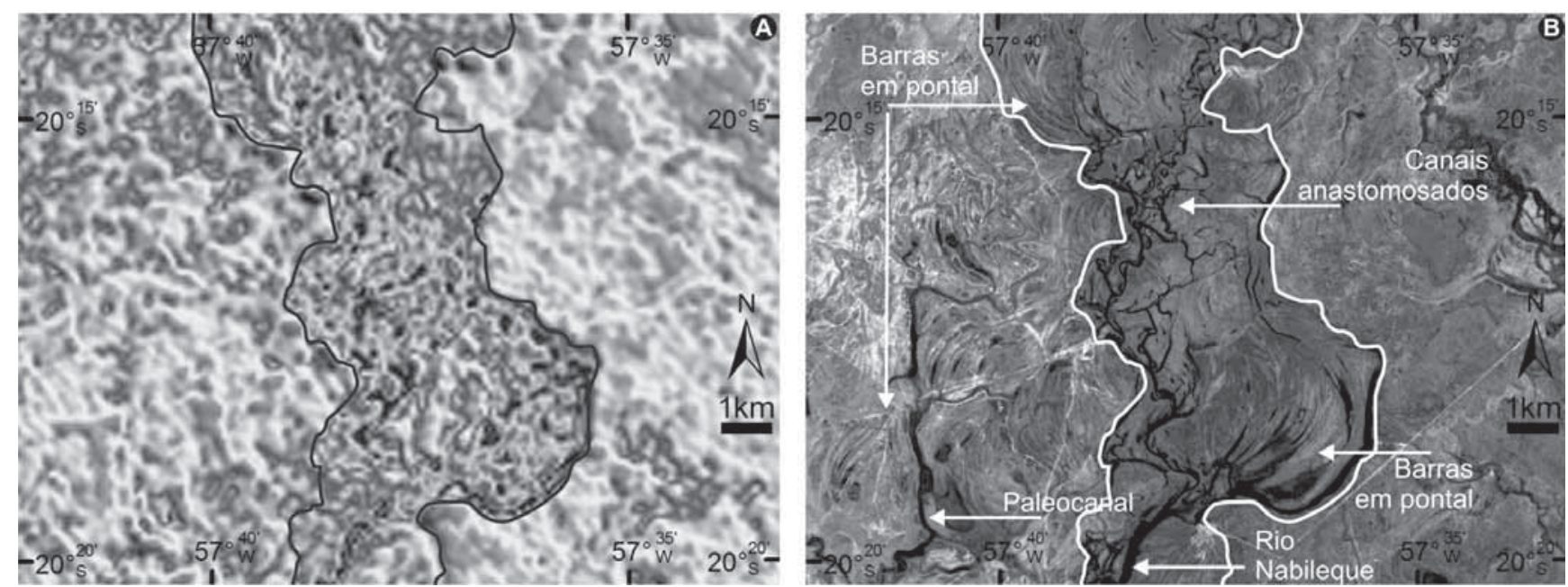

Figura 7 - Limites do cinturão de meandros abandonados onde flui o rio Nabileque são nítidos em MDE (A, localização na figura 5) e em imagens de satélite (B, localização na figura 5, imagem ASTER, R2G3B1, 22/10/2005). O rio Nabileque corta antigos meandros e apresenta padrão anastomosado. Observar que há meandros abandonados e geoformas de barras em pontal na planície aluvial degradada, na margem direita do vale inciso, onde corre o rio Nabileque. 


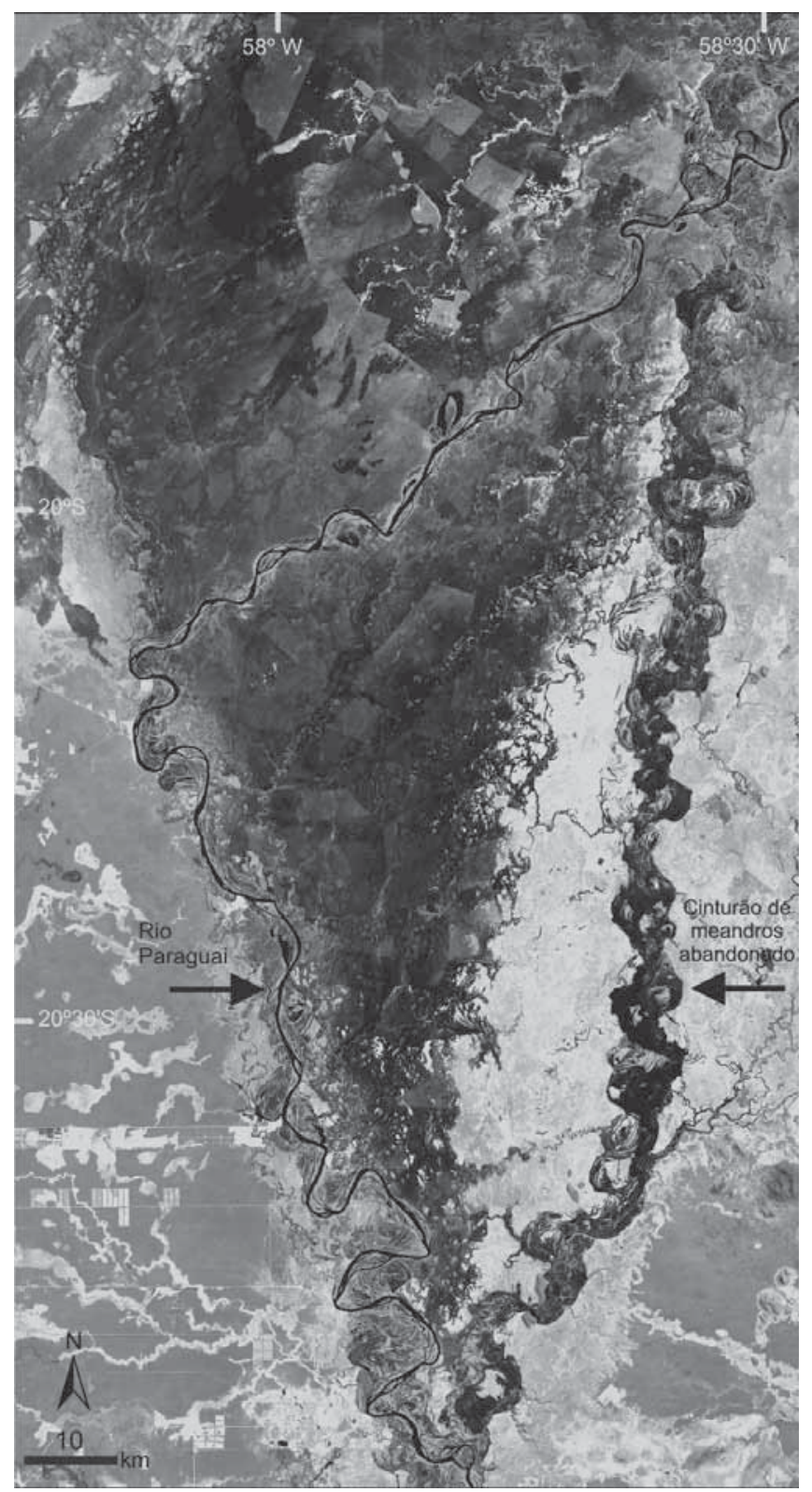

Figura 8 - Pantanal do Nabileque em período de cheia (LandSat 5 TM R5G4B3 de 06/09/2006). A tonalidade escura indica a presença de água, com destaque para a inundação no vale inciso. Destaca-se que a inundação ocorreu em periodo anômalo, já que as cheias ocorrem normalmente de março a junho.

para fora do sistema, que são coletadas pela drenagem periférica composta em parte pelo rio Negro e em parte pelo rio Paraguai, quando este deflete para sudeste.

Os compartimentos geomorfológicos da área são, assim, o resultado da sobreposição de diferentes padrões fluviais, consequência de mudanças climáticas e de tectonismo recente (Assine \& Soares 2004). Os diferentes compartimentos registram mudanças na paisagem e nos processos deposicionais e/ou erosivos, cujas causas estão associadas a processos alogênicos e/ ou autogênicos, cuja atuação na evolução da área ainda está por ser devidamente equacionada.
Entretanto, com base nos resultados alcançados, já é possível estabelecer uma sucessão cronológica de eventos que moldaram a configuração do Pantanal do Nabileque (Fig. 9).

O primeiro evento reconhecido foi a formação dos lobos deposicionais do megaleque. O rio Paraguai, a partir da foz do rio Miranda, assumia padrão distributário com dinâmica sedimentar bastante ativa, marcada pela sucessiva construção e abandono de lobos distributários formados pela deposição dos sedimentos transportados pelo rio. Com base na orientação da paleodrenagem da planície aluvial degradada, a progradação dos lobos foi predominantemente para o quadrante sudoeste até o contato com frentes de progradação dos megaleques dos rios Tucavaca (Bolívia) e Pilcomayo (Paraguai), pertencentes à bacia do Chaco. $\mathrm{O}$ rio Negro (Bolívia), situado no extremo oeste da área estudada, constituiu, no passado, o canal que coletava as águas dos megaleques (Tucavaca, Pilcomayo e Nabileque), representando assim o nível de base regional.

Rebaixamento do nível de base de erosão, concomitante com mudanças climáticas ocorridas do final do Pleistoceno ao início do Holoceno, promoveram dissecação na superfície do leque e formação de vale inciso alinhado na direção norte-sul, por onde passou a fluir o rio Paraguai (Fig. 9). A migração dos meandros causou o alargamento do vale e a formação de um cinturão de meandros no seu interior. A julgar pela dimensão dos paleocanais existentes na planície de meandros abandonados, o rio Paraguai era largo, com vazão compatível com a atual.

A mudança de padrão fluvial, de distributário para tributário meandrante, pode ter sido consequência de aumento da vazão devido ao predomínio de condições climáticas mais úmidas na transição Pleistoceno/Holoceno (Assine \& Soares 2004). Entretanto, incisão fluvial pode ser também decorrência de outras causas, como variações do nível de base de erosão. Processos e feições semelhantes aos encontrados no Nabileque também foram constatados no megaleque do rio Ganga, norte da Índia, onde depósitos aluviais são truncados pelo vale inciso do atual rio Ganga, cuja incisão foi atribuída a mudanças climáticas (Shukla et al. 2001).

Em evento subsequente, ocorreu mudança do curso do rio Paraguai, com a formação do cinturão de meandros atual. Com isso, o antigo cinturão foi abandonado e nele se instalou o rio Nabileque, um rio de menor porte, subajustado em relação às feições fluviais da planície onde corre. Duas hipóteses podem ser aventadas para explicar a mudança de curso do rio Paraguai, uma baseada na ocorrência de avulsão fluvial e outra fundamentada em fenômeno de captura fluvial.

Mesmo que tenha ocorrido avulsão fluvial, fenômeno associado à dinâmica do sistema deposicional (autogênico), não se pode deixar de destacar que o novo canal passou a ter direção NE, coincidente com estruturas rúpteis do Lineamento Transbrasiliano, o que sugere controle tectônico (alogênico). Soares et al. (1998) postularam que o Lineamento Transbrasiliano 

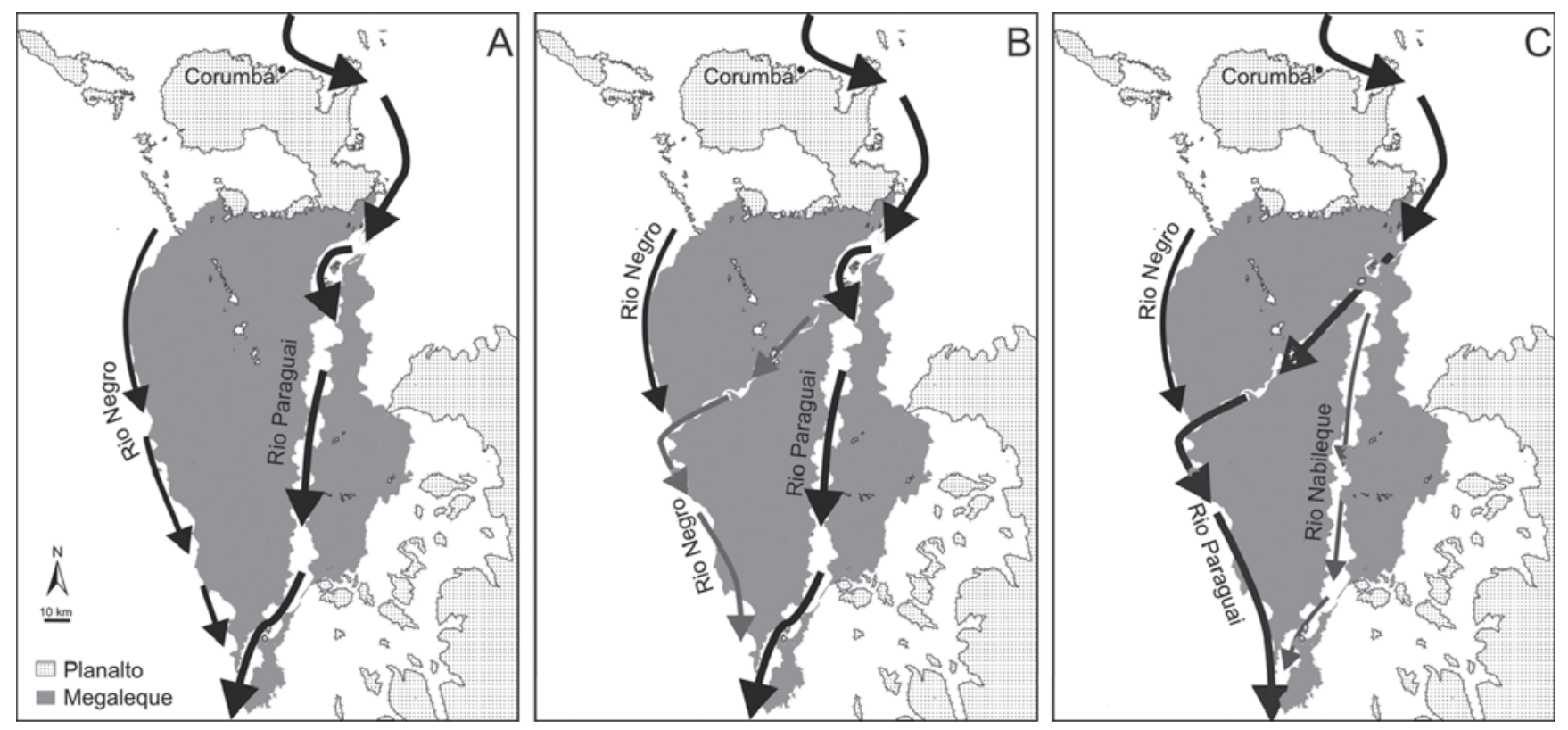

Figura 9 - Esquema evolutivo de mudança do curso do rio Paraguai: A) o rio Paraguai fluía na direção NS em vale inciso; B) evento de avulsão/captura do curso do rio Paraguai, que passou a fluir para SW, com bifurcação do canal; C) o novo curso se estabeleceu no rumo $S W$, com progressivo abandono do antigo cinturão de meandros e instalação do rio Nabileque.

influencia fortemente os processos fluviais na Bacia do Pantanal, cruzando a área do megaleque do Nabileque (Fig. 10). Anteriormente, Ab’Saber (1988) já havia considerado que a mudança de curso do rio Paraguai foi induzida por tectônica residual holocênica.

A mudança do curso do rio Paraguai pode ter sido também resultante de um processo de captura fluvial, o que pressupõe a existência de um afluente do rio $\mathrm{Ne}-$ gro, com nascentes na planície aluvial degradada. Neste caso, a captura seria causada por erosão remontante, das nascentes deste rio até o canal do rio Paraguai (Fig. 9). Como consequência do fenômeno de captura, teria havido subdivisão do canal e, progressivamente, abandono do antigo curso.
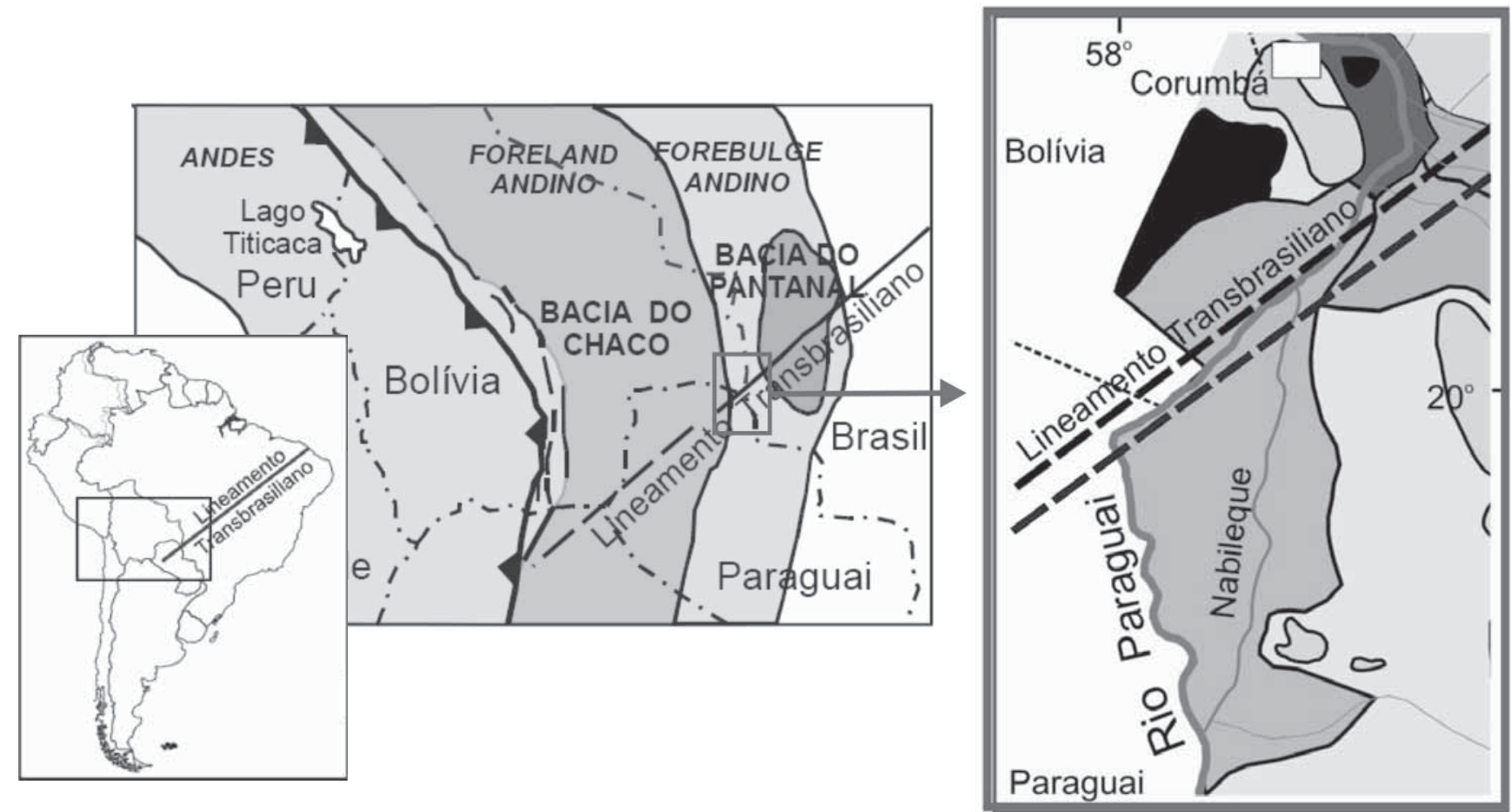

Figura 10 - O curso do rio Paraguai está condicionado por estruturas NE relacionadas ao Lineamento Transbrasiliano (modificado de Assine \& Soares 2004). 
Paleocanais e meandros abandonados existentes na planície degradada evidenciam também ajustes fluviais mais recentes (Fig. 6). Segundo Assine \& Soares (2004) foram resultado de mudanças na hidráulica do rio durante o Holoceno em resposta a mudanças na vazão fluvial. Mudanças climáticas durante o Holoceno, registradas em regiões adjacentes ao Pantanal, corroboram esta interpretação (Iriondo 1993, Stevaux 1994, Parolin et al. 2006).

CONCLUSÃO O Pantanal do Nabileque é uma área de sedimentação continental quaternária que abriga um megaleque fluvial, em grande parte dissecado. A geomorfologia do Nabileque apresenta muitas semelhanças com outras regiões do Pantanal, especialmente o fato de que o sistema deposicional também é um megaleque fluvial. Mas, apresenta três diferenças importantes. Primeiro, destaca-se o fato de que o megaleque do Nabileque é um sistema aluvial peculiar, pois não está associado a rios oriundos de relevos altos situados nos planaltos adjacentes à planície. Segundo, diferentemente dos outros, tem de ser considerado por se tratar de um megaleque fluvial construído pelo próprio rio Paraguai, na saída do rio para a planície do Chaco. Terceiro, porque a maior parte da superfície é uma planície aluvial degradada, sem a presença de um lobo distributário ativo, como é o caso de todos os outros megaleques do Pantanal.
Toda a área estudada abriga um verdadeiro mosaico geomorfológico, com diversos tipos de feições morfológicas geradas durante o Quaternário, resultado de mudanças ambientais ocorridas no megaleque do Nabileque desde o Pleistoceno tardio. A partir do Holoceno, o megaleque deixou de funcionar como um sistema dominantemente distributário e geoformas antigas vêm sendo continuamente obliteradas pela drenagem atual, o que impediu o reconhecimento e mapeamento de antigos lobos deposicionais.

Destaca-se o registro da mudança de curso do rio Paraguai, que pode ter sido decorrente de fenômenos de avulsão ou de captura fluvial, ou da conjugação de ambos os fenômenos. E, como decorrência da mudança de curso, o abandono da antiga planície de meandros e instalação do rio Nabileque, de menor porte em relação aos paleocanais do cinturão de meandros, por isso interpretado como um rio subajustado.

Agradecimentos Os autores agradecem à FAPESP pelo apoio à pesquisa (processo 07/55987-3); à UFMS pelo apoio logístico durante os trabalhos de campo; à professora Edna Maria Facincani pelo apoio e discussões sobre a área; ao CNPq por bolsa PQ concedida a Mario Luis Assine (proc. 305108/2009-3); ao CNPq e à CAPES pela concessão de bolsa de doutorado para Sidney Kuerten, do Programa de Pós-Graduação em Geociências e Meio Ambiente da Unesp, Campus de Rio Claro.

\section{Referências}

Ab'Saber A.N. 1988. O Pantanal Mato-Grossense e a teoria dos refúgios. Revista Brasileira de Geografia - Especial Centenário, 50(2):9-57.

Assine M.L. 2003. Sedimentação na Bacia do Pantanal Mato-Grossense, Centro-Oeste do Brasil. Tese de LivreDocência, Instituto de Geociências e Ciências Exatas, Universidade Estadual Paulista, Rio Claro, 106 p.

Assine M.L. 2004. A bacia sedimentar do Pantanal MatoGrossense. In: Mantesso Neto V., Bartorelli A., Carneiro C.D.R., Brito Neves B.B. (eds.) Geologia do continente sul-americano: evolução da obra de Fernando Flávio Marques de Almeida. São Paulo, Beca, p. 61-74.

Assine M.L. 2005. River avulsions on the Taquari megafan, Pantanal wetland, Brazil. Geomorphology, 70:357-371.

Assine M.L. \& Silva A. 2009. Contrasting fluvial styles of the Paraguay River in the northwestern border of Pantanal wetland, Brazil. Geomorphology, 113:189-199.

Assine M.L. \& Soares P.C. 2004. Quaternary of the Pantanal, west-central Brazil. Quaternary International, 114:23-24.

Assine M.L., Padovani C.R., Zacharias A.A., Angulo R.J., Souza M.C. 2005. Compartimentação geomorfológica, processos de avulsão fluvial e mudanças de curso do Rio Taquari, Pantanal Mato-Grossense. Revista Brasileira de Geomorfologia, 6:97-108.

Bhang K.J., Schwartz F.W., Braun A. 2007. Verification of the vertical error in C-band SRTM DEM. IEEE, Transactions on geoscience and remote sensing, 45(1):36-44.
Iriondo M. 1993. Geomorphology and Late Quaternary of the Chaco (south America). Geomorphology, 13:289-303.

Litton G. 1987. Introduction to database management: a practical approach. Dubuque, William C. Brown Pub., $532 \mathrm{p}$.

Parolin M., Medeanic S., Stevaux J.C. 2006. Registros palinológicos e mudanças ambientais durante $\mathrm{O}$ Holoceno de Taquarussu (MS). Revista Brasileira de Paleontologia, 9:137-148.

Shukla U.K., Singh I.B., Sharma M., Sharma S. 2001. A model of alluvial megafan sedimentation: Ganta Megafan. Sedimentary Geology, 144:243-262.

Sippel S.J., Hamilton S.K., Silva J.S.V., Melack J.M. 1995. Passive microwave remote sensing of flooding in the Pantanal. In: INPE/EMBRAPA, Encontro sobre Sensoriamento Remoto Aplicado a Estudos no Pantanal, 1, Resumos, p. 105-107.

Soares P.C., Assine M.L., Rabelo L. 1998. The Pantanal Basin: recent tectonics, relationships to the Transbrasiliano Lineament. In: INPE, Simpósio Brasileiro de Sensoriamento Remoto, 9, Anais, p. 459-469.

Soares A.P., Soares P.C., Assine M.L. 2003. Areiais e lagoas do Pantanal, Brasil: herança paleoclimática?. Revista Brasileira de Geociências, 33:211-224.

Stevaux J.C. 1994. Upper Paraná River (Brazil) geomorphology and paleoclimatology. Quaternary International, 21:143-161. 
Tricart J. 1982. El Pantanal: un ejemplo del impacto geomorfologico sobre el ambiente. Informaciones Geograficas, 29:81-97.

Zani H., Assine M.L., Silva A., Corradini F.A., Kuerten S., Gradella F. 2009. Geoformas deposicionais e feições erosivas no Pantanal Mato-Grossense identificadas por sensoriamento remoto. Geografia, 34:643-654.
Zeiler M. 1999. Modeling Our World. The ESRI Guide to Geodatabase Design. California, ESRI Press, 202 p.

Manuscrito ID 17935

Submetido em 03 de julho de 2010

Aceito em 21 de dezembro de 2011 